\title{
Can a Bengali version of Epworth Sleepiness Scale evaluate excessive daytime sleepiness: a validity study
}

\author{
Rantu Paul*, Saswata Chatterjee**, Rana Dey*, Madan Sarma*, \\ Goutam Jana*, Saikat Nag\#, Sujan Bardhan\#, Parthasarathi \\ Bhattacharyya\# \\ *Clinical research assistant, ${ }^{* *}$ Research fellow, \# Consultant
}

Indian J Sleep Med 2011 ; 6.3, 102-104

\begin{abstract}
Background: Excessive daytime sleepiness (EDS) is an indicator of sleep disordered breathing (SDB) and the Epworth sleepiness scale (ESS) is a popular instrument to evaluate EDS subjectively. Although translated and validated in different languages including Hindi, but there has been no available and validated Bengali version of ESS so far.

Methods: The original English version of ESS has been translated in Bengali and thereafter cross translated in English with proper human resources. The accepted Bengali version was then given to 30 patients of obstructive sleep apnea (OSA) and 30 normal individuals (based on polysomnographic diagnosis) along with the original English version to respond. The mean score of responses for both the versions were thereafter compared.

Results: There was no significant difference on statistical analysis between the means obtained from using the two versions of ESS.

Conclusion: The Bengali version of ESS is thus found valid and reliable and can be successfully used.

Keywords: Epworth sleepiness scale (ESS), excessive daytime sleepiness (EDB), validation, obstructive sleep apnea (OSA), Sleep Disorder Breathing (SDB), Chronic Obstructive Airway Disease (COAD), Body Mass Index (BMI)
\end{abstract}

\section{Introduction}

$\mathrm{E}$ DS is the most important symptom of OSA ${ }^{1}$. It can give rise to several problems as fatigue, ness, lack of energy, work place accidents and others ${ }^{2,3}$. Detection and measurement of EDS is thus important.

\section{Address for correspondence} Dr. Parthasarathi Bhattacharyya CB - 16, Sector - I, Salt Lake, Kolkata - 700064 Phone: 033-2358 0424

e-mail: parthachest@yahoo.com
Objective measurement of EDS with tests like MSLT (Multi Sleep Latency Test) ${ }^{4}$ is difficult and mostly not feasible for the lack of a proper sleep lab. However, based on subjective assessment on documented response to 8 questions on a scale of 0 to 3 , ESS has been a successful mode of assessment of the degree of EDS.

Though translated and used in several languages (Hindi, Spanish, German, Italy etc. $)^{5,6,7,8}$, there is no Bengali version of ESS.

In this study we translated ESS in Bengali keeping the meaning of the original version intact and tried to 
validate the translated questionnaire.

\section{Methods}

Both 'Case' (OSA patients) and 'Control' (persons without OSA) were included in the study. The subjects, upon written informed consent underwent a full night PSG (polysomnography) with Embla machine (EMBLA, S 7000; Medcare Flaga, Iceland). Absence of significant COAD (Gold III \& IV) and inability to freely read and write both or either of the languages (English and Bengali) were looked for before incorporating the volunteers for the study.

The English and the Bengali versions of ESS were given to the subjects before and after PSG respectively. The responses were later sorted to either case or control group for analysis.

\section{Statistical calculation}

The responses were recorded in Microsoft Excel Worksheet, 2003. Means and standard deviations (SD) were calculated in excel sheet. Difference between two means was tested by the student's 't' test by Epical Software 2000.
Table 1: Demographic details of cases and controls

\begin{tabular}{|l|l|l|l|}
\hline Parameters & Case mean \pm SD & Control mean \pm SD & p-value \\
\hline Age (yrs.) & $52.90 \pm 8.23$ & $49.37 \pm 13.18$ & 0.21 \\
\hline BMI (Kg/mt $\left.{ }^{2}\right)$ & $30.79 \pm 4.91$ & $28.59 \pm 5.16$ & 0.09 \\
\hline $\begin{array}{l}\text { Neck circum- } \\
\text { ference (c.m.) }\end{array}$ & $42.53 \pm 4.26$ & $38.78 \pm 3.43$ & $0.0004 \#$ \\
\hline $\begin{array}{l}\text { Waist circum- } \\
\text { ference (c.m.) }\end{array}$ & $109.85 \pm 12.35$ & $103.36 \pm 10.05$ & $0.03 \#$ \\
\hline $\begin{array}{l}\text { Initial } \\
\text { saturation (\%) }\end{array}$ & $95.93 \pm 2.45$ & $97.20 \pm 1.52$ & $0.02 \#$ \\
\hline
\end{tabular}

\# Statistically significant

\section{Results}

Out of 60 subjects 46 were male and mean age was 51.13 $( \pm 11.04)$ years. The mean sleep time was $386.00( \pm 124.08)$ minutes and mean BMI was $29.69( \pm 5.11) \mathrm{kg} / \mathrm{mt}^{2}$.

Out of 30 subjects in case group 25 were male and their mean age and BMI were $52.90( \pm 8.23)$ years and $30.79( \pm 4.91) \mathrm{kg} / \mathrm{mt}^{2}$ respectively. Details are mentioned in Table 1.

The means of ESS (in English version) and ESS (in Bengali version) of case group were $13.73( \pm 5.45)$ and 13.57 ( \pm 5.29$)$ respectively and difference is not statistically significant $(\mathrm{t}=0.12$, $\mathrm{p}$-value $=0.91)$. The means of ESS (in English version) and ESS (in Bengali version) of control group were $9.27( \pm 4.14)$ and $9.40( \pm 4.47)$ respectively and the difference is also statistically

Table 2: Comparison of ESS English and ESS Bengali in both cases and controls

\begin{tabular}{|l|l|l|l|l|l|l|}
\hline ESS questions & \multicolumn{2}{|l|}{ Case } & \multicolumn{2}{l|}{ Control } \\
\hline & $\begin{array}{l}\text { ESS in English } \\
(\text { Mean } \pm \text { SD) }\end{array}$ & $\begin{array}{l}\text { ESS in Bengali } \\
(\text { Mean } \pm \text { SD) }\end{array}$ & p-value & $\begin{array}{c}\text { ESS in English } \\
\text { Mean } \pm \text { SD) }\end{array}$ & $\begin{array}{l}\text { ESS in Bengali } \\
(\text { Mean } \pm \text { SD) }\end{array}$ & p-value \\
\hline Sitting and reading & $1.50 \pm 1.20$ & $1.53 \pm 1.14$ & 0.92 & $1.20 \pm 1.03$ & $1.17 \pm 1.05$ & 0.91 \\
\hline Watching television & $1.70 \pm 1.12$ & $1.83 \pm 1.21$ & 0.66 & $1.20 \pm 0.92$ & $1.30 \pm 1.09$ & 0.70 \\
\hline $\begin{array}{l}\text { Sitting inactive in a public } \\
\text { place }\end{array}$ & $1.77 \pm 1.04$ & $1.77 \pm 1.04$ & 1.00 & $1.00 \pm 0.87$ & $0.97 \pm 0.93$ & 0.89 \\
\hline $\begin{array}{l}\text { As a passenger in a car/bus } \\
\text { for an hour without a break }\end{array}$ & $2.20 \pm 1.06$ & $2.10 \pm 1.06$ & 0.71 & $1.67 \pm 1.09$ & $1.60 \pm 1.13$ & 0.80 \\
\hline $\begin{array}{l}\text { Lying down to rest in the } \\
\text { afternoon when } \\
\text { circumstances permit }\end{array}$ & $2.63 \pm 0.61$ & $2.67 \pm 0.76$ & 0.82 & $1.97 \pm 1.03$ & $1.93 \pm 1.01$ & 0.88 \\
\hline $\begin{array}{l}\text { Sitting and talking to } \\
\text { someone }\end{array}$ & $0.73 \pm 0.87$ & $0.67 \pm 0.88$ & 0.79 & $0.20 \pm 0.41$ & $0.20 \pm 0.48$ & 1.00 \\
\hline $\begin{array}{l}\text { Sitting quietly after a lunch } \\
\text { without alcohol }\end{array}$ & $2.20 \pm 1.00$ & $2.20 \pm 0.96$ & 1.00 & $1.40 \pm 0.93$ & $1.47 \pm 0.86$ & 0.76 \\
\hline $\begin{array}{l}\text { In a car, while stopped } \\
\text { for a few minutes traffic }\end{array}$ & $1.00 \pm 1.08$ & $0.80 \pm 1.00$ & 0.46 & $0.63 \pm 0.89$ & $0.80 \pm 0.96$ & 0.48 \\
\hline ESS total score & $13.73 \pm 5.45$ & $13.57 \pm 5.29$ & 0.91 & $9.27 \pm 4.14$ & $9.40 \pm 4.47$ & 0.91 \\
\hline
\end{tabular}


insignificant $(\mathrm{t}=0.12$, $\mathrm{p}$-value $=0.91)$. Both versions of ESS in either case are compared in table 2.

\section{Discussion}

SDB is a common problem and a manifestation of several disease states as narcolepsy, idiopathic hypersomnolence, OSA etc. Out of them, OSA remains the most important and frequent but most neglected public health problem and has been the cause of significant mortality and morbidity ${ }^{9}$. Awareness of the likely presence of OSA is thus a very important issue to be disseminated to the society and assessment of the presence of symptoms is important for the general practitioners. Incidentally, SBD is the most important and the commonest symptom of OSA ${ }^{1}$. It has been found that the degree of the presence of OSA has been co-related to the degree of EDS ${ }^{10}$. Thus measurement of EDS has become an important issue to the physicians in general. Several objective and subjective methods are forwarded for the measurement SDB. However, ESS being a subjective one is the most simple to practice.

Although subjective, ESS has been the most popular one because of its simplicity ${ }^{11}$. It is based on reply to 8 questions on a scale of 0 to 3 as ' $0=$ no chance of dozing', ' 1 = slight chance of dozing', ' $2=$ moderate chance of dozing' and ' 3 = high chance of dozing'. Although the sensitivity and the specificity of screening OSA is low with ESS, it is found to be useful for assessment of narcolepsy, idiopathic hypersomlence, and other conditions associated with $\operatorname{EDS}^{12,13,14}$. Hence, a widespread use of ESS is strongly warranted and this demands the use of this simple instrument in different languages other than English. Incidentally, Hindi version of ESS is already validated ${ }^{6}$; yet it is not enough since, the mother tongue of the majority of the countrymen is not Hindi although many people can understand the language to a good extent, very few can read or write.

In our observation, as expected, there has been an obvious difference in the BMI, waist and neck circumferences between the case and the control group but there were no difference in response to individual questions (both the Bengali and the English version) in both the groups. Most of our patients happen to be non alcoholic and do not possess a car or travel by car frequently. Hence, although they had no problem of understanding the question, the response was forthcoming on equating car with bus or other public transport. Therefore, for the question no 7 in particular, the option of bus etc. should be kept in addition to car. The translated and validated version of the ESS is thus likely to help our physicians and the patients to assess the EDS and take proper measures to preserve health of the public.

\section{References}

1. American Sleep Disorders Association. The International Classification of sleep disorders. Rochester, Mnn, 1990.

2. Sleepiness, Fatigue, Tiredness, and Lack of Energy in Obstructive Sleep Apnea. Ronald D. Chervin. CHEST 2000; 118:372-379.

3. Dinges DF. An overview of sleepiness and accidents. J Sleep Res. 1995;4(2):4-14.

4. Carskadon $\mathbf{M}$, Dement WC, Mitler MM, Roth T, Westbrook PR, Keenam S. Guidelines for the multiple sleep latency test (MSLT): a standard measure of sleepiness. Sleep 1986; 9:519-24.

5. Bhatia M, Prasad K, Pande RN. Hindi Version of Epworth Sleepiness Scale: A Validity Study. Indian J Sleep Med 2006; 1.4,208-210.

6. Izqulerdo-Vicario $\mathbf{Y}$, Ramos-Platon MJ, Conesa-Peraleja D, Lozano-Parra AB, Espinar-Sierra J. Epworth Sleepiness Scale in a sample of the Spanish Population. Sleep 1997; 20:676-7.

7. Bloch KE, Schoch OD, Zhang JN, Russi EW. German version of the Epworth Sleepiness Scale. Respiration 1999;66:440-7.

8. L. Vignatelli, G Plazzi, A. Barbato, L. Ferini-Strambi, R. Manni, et al. Italian Version of the Epworth Sleepiness scale: external validity. Neurol Sci (2003) 23: 295-300.

9. J. F. Pagel, Obstructive Sleep Apnea (OSA) in Primary Care: Evidence-based Practice. J Am Board Fam Med 2007;20: 392-398.

10. Udaya Seneviratneab, Kathiravelu Puvanendranab. Excessive daytime sleepiness in obstructive sleep apnea: prevalence, severity, and predictors. Sleep Medicine. Volume 5, Issue 4, Pages 339-343 (July 2004).

11. Murry W. Jones. A New Method for Measuring Daytime Sleepiness: The Epworth Sleepiness Scale. Sleep 1991; 14(6):540-545.

12. Van den Hoed J, Kraemer H, Guilleminault $C$, Zarcone VP, Miles LE, Dement WC, Mitler MM. Disorders of excessive daytime somnolence: polygraphic and clinical data for 100 patients. Sleep 1981;4:23-37.

13. Parkes JD, Chen SY, Chift SJ, Dahlitz MJ, Dunn G. The clinical diagnosis of the narcoleptic syndrome. J Sleep Res 1998; 7: 41-52.

14. Chung KF. Use of the Epworth Sleepiness Scale in Chinese patients with obstructive sleep apnea and normal hospital employees. Journal of Psychosomatic Research 2000; 49: 367-372. 